\title{
Positive effects of a chicken eggshell powder-enriched vitamin-mineral supplement on femoral neck bone mineral density in healthy late post-menopausal Dutch women
}

\author{
Anne Schaafsma ${ }^{1}$, Jasper J. van Doormaal ${ }^{2}$, Frits A. J. Muskiet ${ }^{2}$, Gert J. H. Hofstede ${ }^{2}$, Igor Pakan ${ }^{3}$ and \\ Eveline van der Veer $^{2}$ \\ ${ }^{1}$ Department of Research \& Development Leeuwarden, Friesland Coberco Dairy Foods, Leeuwarden, The Netherlands \\ ${ }^{2}$ Groningen University Hospital, Groningen, The Netherlands \\ ${ }^{3}$ Medical Centre Leeuwarden, Leeuwarden, The Netherlands
}

(Received 27 February 2001 - Revised 19 November 2001 - Accepted 28 November 2001)

\begin{abstract}
Although bone metabolism is largely under genetic control, the role of nutrition is considerable. The present study evaluates the effects of chicken eggshell powder, a new source of dietary $\mathrm{Ca}$, and purified $\mathrm{CaCO}_{3}$ on bone mineral density (BMD) of the lumbar spine and hip. Besides BMD we also looked at biochemical markers of bone and Ca metabolism. Both Ca sources were provided in combination with minerals and vitamins including $\mathrm{Mg}$, cholecalciferol and phylloquinone. We designed a randomised, double-blind, placebo-controlled study to take place over 12 months. Healthy Caucasian women ( $n 85)$, selected by age ( $\geq 50$ and $<70$ years), from the databases of general practitioners were recruited by telephone calls. They had to be at least 5 years post-menopausal, with lumbar spine T-score being $>-2 \cdot 5$. At baseline, their mean habitual daily $\mathrm{Ca}$ intake was adequate. The women were randomly allocated to: eggshell powderenriched (group $\mathrm{A} ; n$ 24), purified $\mathrm{CaCO}_{3}$-enriched (group $\mathrm{B} ; n 22$ ), or a placebo product (group $\mathrm{C} ; n$ 27). BMD was measured at baseline and then after 6 and 12 months of supplementation as were the biochemical markers bone-specific alkaline phosphatase, amino-terminal propeptide extension of type I collagen, deoxypyridinoline, calcitonin, intact parathyroid hormone, calcidiol, and urinary Ca. After 12 months of supplementation, only mean BMD of the femoral neck in group A was significantly increased $(P=0.014)$ by $1.75 \%(95 \%$ CI $0.18,3.32)$ compared with a decrease of $-0.60 \%(95 \% \mathrm{CI}-1.92,0.72)$ in group C. This increase coincided with significant decreases in markers of bone resorption and formation. No significant changes were seen in BMD at other sites, including lumbar spine, nor in groups B and C. No differences were found between groups $\mathrm{A}$ and $\mathrm{B}$, or B and C.

The present study indicates that healthy late post-menopausal women with an adequate $\mathrm{Ca}$ intake at baseline may increase BMD of the hip within 12 months following supplementation with the chicken eggshell powder-enriched supplement.
\end{abstract}

Eggshell powder: Calcium carbonate: Bone mineral density: Postmenopausal women

Age-related decrease in bone mass and loss of bone architecture contribute to bone fragility. Nutritional prevention strategies, aiming to reduce the risk of fragility fractures, should therefore start as soon as possible. For women, bone loss accelerates at the onset of menopause as a result of a decreased production of oestrogen. This loss is often not due to nutrient deficiency and cannot substantially be influenced by the diet. Before bone has come into a new steady state, 5 to 10 years have passed. Nutritional interventions therefore seem to be most effective following that period (Heaney, 1996).

At least $\mathrm{Ca}$ and vitamin $\mathrm{D}$ are recognised as important in primary prevention strategies and should be present in nutritional supplements. However, also for $\mathrm{Mg}$ and vitamin $\mathrm{K}$, evidence for positive effects on bone is compelling (Schaafsma et al. 2001). Mg is thought to prevent Ca leakage from bone by regulating the $\mathrm{pH}$ of extracellular fluid. Furthermore, it is necessary for the synthesis of calcitriol

\footnotetext{
Abbreviations: BMD, bone mineral density; D-Pyr, deoxypyridinoline; 25(OH) D, calcidiol; P1NP, amino-terminal extension of type I collagen; PTH,
} parathyroid hormone.

* Corresponding author: Dr Anne Schaafsma, fax +31 58 2992540, email a.schaafsma@FDF.nl 
(Driessens \& Verbeeck, 1988). Two studies with postmenopausal women suggest an effect of $\mathrm{Mg}$ on bone mineral density (BMD) of hip (Rude \& Olerich, 1996) and forearm (Stendig-Lindberg et al. 1993) after 2 years of supplementation with 250 and $500 \mathrm{mg}$ daily. Vitamin $\mathrm{K}$ is an essential co-factor in post-translation carboxylation of osteocalcin, which is important for proper mineralization of new bone (Sokoll et al. 1997). Post-menopausal women with fractures of the distal radius were found to have a low percentage of carboxylated osteocalcin. These levels increased considerably following supplementation with $1 \mathrm{mg}$ phylloquinone/d for only 2 weeks (Douglas et al. 1995). Recently we showed that also relatively small daily doses of phylloquinone $(80 \mu \mathrm{g})$ can increase plasma carboxylated osteocalcin levels in post-menopausal women (Schaafsma et al. 2000). Several studies have shown positive effects of additional $\mathrm{Ca}$ and/or vitamin $\mathrm{D}$ on BMD of the lumbar spine and hip. These effects are associated with decreased fracture risk (Prince et al. 1995; Dawson-Hughes et al. 1997; Riggs et al. 1998; Kanis, 1999). The amounts of Ca and vitamin D necessary for maximum effect are debated (McKane et al. 1996; Dawson-Hughes, 1998; Vieth 1999). The Ca source used may influence the final effect on BMD.

Chicken eggshell powder is a rather unknown $\mathrm{Ca}$ source. It contains about $39 \%$ (w/w) elemental Ca with a bioavailability as high as from $\mathrm{CaCO}_{3}$ (Schaafsma \& Beelen, 1999). Since it is widely available, it may be a cheap and effective solution for many $\mathrm{Ca}$-deficient populations. It is of interest to know that chicken eggshell powder also contains $\mathrm{Sr}$ (on average $380 \mu \mathrm{g} / \mathrm{g}$ ). This micronutrient may have an anabolic effect on bone (Reginster et al. 1999). In small studies, eggshell powder showed positive effects on BMD of the lumbar spine and hip in post-menopausal women with osteoporosis (Makai \& Chudacek, 1991; Schaafsma \& Pakan, 1999).

Suitable parameters to measure effects of nutritional intervention on bone in a healthy population are BMD for bone strength (Kanis, 1999), deoxypyridinoline (DPyr) for bone resorption (Delmas, 1991), and bone-specific alkaline phosphatase and the amino-terminal propeptide extension of type I collagen (P1NP; Cabrera et al. 1998) for bone formation. Carboxylated osteocalcin, expressed as a percentage from total osteocalcin, is a marker of bone mineralisation and vitamin $\mathrm{K}$ status (Boskey et al. 1998). Parathyroid hormone (PTH) and calcitonin are regulators of $\mathrm{Ca}$ metabolism and provide information about bone remodelling (Aurbach, 1988). Vitamin D status is reflected by serum levels of calcidiol $(25(\mathrm{OH}) \mathrm{D})$ which is the precursor of calcitriol (McKenna \& Freaney, 1998).

The present paper describes a double-blind, placebocontrolled, randomised study with healthy Caucasian post-menopausal women. The aim of the study was to investigate the effects of two different $\mathrm{Ca}$ sources, chicken eggshell powder and purified $\mathrm{CaCO}_{3}$, on BMD of the lumbar spine and hip. To support the BMD measurements, changes in biochemical markers of bone formation (P1NP, bone-specific alkaline phosphatase, osteocalcin), bone resorption (D-Pyr) and vitamin $\mathrm{K}$ status in bone (undercarboxylated osteocalcin) were measured. In addition markers of vitamin D status (25(OH)D) and Ca metabolism
(PTH and calcitonin) were also measured. Both Ca sources were given in combination with other minerals and vitamins, including $\mathrm{Mg}$ and the vitamins cholecalciferol and phylloquinone. Comparisons were made between the two Ca sources, with baseline, and with placebo.

\section{Methods \\ Subjects}

Apparently healthy Caucasian post-menopausal women ( $n$ 85) were selected from databases of three general practitioners in the village of Eelde in The Netherlands. Selection criteria used were age ( $\geq 50$ and $<70$ years), absence of acute and chronic illnesses, and no use of medicines known to interfere with bone metabolism. The general practitioner assistants asked selected women, by telephone, if they were interested to participate in the study. The research assistant visited interested women for the final inclusion criteria. Women included were at least 5 years post-menopausal, did not use vitamin and/or mineral preparations known to interfere with bone metabolism, and they were asked to abstain from artificial sunbathing during the study period. Finally, following the first dual-energy X-ray absorptiometry, women with a lumbar spine T-score $<-2.5$ or evident arthrosis of the lumbar spine or hip, confirmed by X-ray photography, were excluded. Post-menopausal age was determined by recall. Participants were included after informed consent was obtained. Baseline characteristics are given in Table 1. During the study twelve women dropped out because of the need for medical treatments not related to the intervention. The Medical Ethical Committee of the University Hospital of Groningen approved the study.

\section{Supplements and diet}

Women were randomly allocated to one of three intervention groups. The three supplements used (Table 2) were chicken eggshell powder (Biomin a.s., Cifer, Slovak Republic) combined with $\mathrm{Mg}$, cholecalciferol, phylloquinone, and a standard mixture of minerals and vitamins (supplement A), or purified $\mathrm{CaCO}_{3}$ (Calcipural GP; Scora S.A., Caffiers, France) combined with the same amounts of minerals and vitamins as supplement A (supplement $\mathrm{B}$ ), or a placebo product containing $2.5 \mathrm{~g}$ skimmed milk powder (supplement $\mathrm{C}$ ). The subjects were instructed to take the supplements twice daily, suspended in water, yoghurt or milk. Compliance, expressed as the percentage of sachets taken, was assessed on the basis of emptied sachet counts and written checklists. A minimum compliance of $75 \%$ was necessary for evaluation of results. The intake of $\mathrm{Ca}$ was recorded at three occasions during the study period by means of a food frequency questionnaire (National Osteoporosis Foundation, 1999). The aim was to classify $\mathrm{Ca}$ intake as low $(<800 \mathrm{mg} / \mathrm{d})$, median $(800-$ $1000 \mathrm{mg} / \mathrm{d})$ or high $(>1000 \mathrm{mg} / \mathrm{d})$.

\section{Materials and methods}

Evening weight and height were measured by standardised 
Table 1. Baseline characteristics of the study subjects (Mean values with their standard deviations)

\begin{tabular}{|c|c|c|c|c|c|c|}
\hline \multirow[t]{2}{*}{ Group*... } & \multicolumn{2}{|c|}{$A$} & \multicolumn{2}{|c|}{$\mathrm{B}$} & \multicolumn{2}{|c|}{ C } \\
\hline & Mean & SD & Mean & SD & Mean & SD \\
\hline Age (years) & $60.5 \dagger$ & 3.6 & 59.5†† & $3 \cdot 8$ & 63.5 & $4 \cdot 0$ \\
\hline Post-menopausal age (years) & $9.9 \dagger \dagger$ & $4 \cdot 0$ & $12 \cdot 1$ & $6 \cdot 4$ & $14 \cdot 3$ & $4 \cdot 6$ \\
\hline Weight (kg) & 71.4 & $9 \cdot 0$ & $75 \cdot 5$ & $10 \cdot 4$ & $76 \cdot 9$ & $11 \cdot 9$ \\
\hline Height (cm) & $164 \cdot 2$ & $5 \cdot 4$ & $164 \cdot 5$ & $5 \cdot 7$ & $163 \cdot 9$ & $6 \cdot 1$ \\
\hline BMI $\left(\mathrm{kg} / \mathrm{m}^{2}\right)$ & $26 \cdot 5$ & 3.2 & $28 \cdot 1$ & 4.8 & $28 \cdot 7$ & 4.4 \\
\hline \multicolumn{7}{|l|}{ Lumbar spine (AP) } \\
\hline T-score & -0.97 & 0.96 & -0.73 & 0.89 & -0.72 & $1 \cdot 17$ \\
\hline Z-score & 0.51 & 1.00 & 0.68 & 0.87 & 0.98 & $1 \cdot 16$ \\
\hline \multicolumn{7}{|l|}{ Femoral neck } \\
\hline T-score & -1.54 & 0.95 & -1.53 & 0.95 & -1.06 & $1 \cdot 12$ \\
\hline Z-score & 0.26 & 1.04 & 0.05 & 0.78 & 0.86 & 1.07 \\
\hline \multicolumn{7}{|l|}{ Total proximal femur } \\
\hline T-score & -0.92 & 0.83 & -0.77 & 1.01 & -0.49 & 1.00 \\
\hline Z-score & 0.20 & 0.86 & 0.29 & 1.03 & 0.81 & 0.92 \\
\hline
\end{tabular}

AP, anteroposterior position.

* Group A ( $n$ 24), eggshell powder-enriched supplement in combination with minerals and vitamins; Group B ( $n$ 22), purified calcium carbonate-enriched supplement in combination with minerals and vitamins; Group C ( $n$ 27), placebo containing $2.5 \mathrm{~g}$ skimmed milk powder.

Mean values were significantly different from those of group $\mathrm{C}: ~ \dagger P<0.05, \uparrow \dagger P<0.01$.

methods, and BMI was calculated $\left(\mathrm{kg} / \mathrm{m}^{2}\right)$. BMD of the lumbar spine (L1-L4) in anteroposterior position and of the hip (total proximal femur, femoral neck, trochanter, intertrochanter, and Ward's triangle) was assessed by dual-energy X-ray absorptiometry on a Hologic QDR 1000 (Hologic Inc., Waltman, MA, USA). The CV was $1 \%$ for the spine and $1.6 \%$ for the hip. Those measurements were done at the start and after 6 and 12 months of intervention. Blood samples were obtained between 19.00 and 21.00 hours at baseline (September-December) and after 6 (March-June) and 12 months (SeptemberDecember). Serum was stored at $-20^{\circ} \mathrm{C}$ within $1 \mathrm{~h}$. Second morning urine samples were collected before food intake and stored in a freezer until analysis. For standard monitoring, serum albumin, total $\mathrm{Ca}$, phosphate, creatinine, $\gamma$ glutamyl transferase, alanine amino transferase and aspartate amino transferase were measured (Mega automated analyser; Merck, Darmstadt, Germany or Vitros; Johnson \& Johnson Diagnostic, Rochester, NY, USA). Bone formation was studied by assessment of P1NP (RIA; Orion Diagnostica, Espoo, Finland; intraand inter-assay CV were $8.4 \%$ and $9.0 \%$ respectively), bone-specific alkaline phosphatase (Immuno assay; Metra Biosystems, Mountain View, CA, USA; intra- and interassay CV were $4.9 \%$ amd $5.5 \%$ respectively), and total osteocalcin and undercarboxylated osteocalcin before and

Table 2. Composition of the supplements (per sachet) for groups A, B and C*

\begin{tabular}{|c|c|c|c|c|}
\hline Nutrient & Group A & Group B & Group C & US RDA \\
\hline Energy (kJ) & 3.4 & $3 \cdot 4$ & 34 & 7980 \\
\hline Protein (g) & 0.2 & 0.2 & 0.7 & 50 \\
\hline \multicolumn{4}{|l|}{$\mathrm{Ca}$} & 1200 \\
\hline \multirow{2}{*}{$\begin{array}{l}\text { From eggshell }(\mathrm{mg}) \\
\text { purified } \mathrm{CaCO}_{3}(\mathrm{mg}) \\
\text { from milk }(\mathrm{mg})\end{array}$} & 500 & & & \\
\hline & \multicolumn{2}{|r|}{500} & 25 & \\
\hline $\mathrm{Mg}(\mathrm{mg})$ & 175 & 175 & $2 \cdot 8$ & 320 \\
\hline $\mathrm{Zn}(\mathrm{mg})$ & 5 & 5 & 0.08 & 12 \\
\hline Si $(\mu \mathrm{g})$ & 1000 & 1000 & about 70 & $\dagger$ \\
\hline Vitamin A ( $\mu \mathrm{g} R E)$ & 160 & 160 & 3 & 800 \\
\hline Cholecalciferol ( $\mu \mathrm{g})$ & 5 & 5 & 0.005 & 10 \\
\hline Vitamin $\mathrm{E}(\mathrm{mg} \alpha$-TE $)$ & 5 & 5 & 0.007 & 8 \\
\hline Phylloquinone $(\mu \mathrm{g})$ & 40 & 40 & 0.23 & 65 \\
\hline Vitamin C $(\mathrm{mg})$ & 30 & 30 & $0 \cdot 12$ & 60 \\
\hline Thiamine $(\mu \mathrm{g})$ & 700 & 700 & 4.6 & 1000 \\
\hline Riboflavin ( $\mu \mathrm{g})$ & 800 & 800 & 35 & 1200 \\
\hline Vitamin $B_{6}(\mu \mathrm{g})$ & 1000 & 1000 & $9 \cdot 2$ & 1600 \\
\hline Vitamin $B_{12}(\mu \mathrm{g})$ & 0.5 & 0.5 & 0.09 & $2 \cdot 0$ \\
\hline \multicolumn{5}{|c|}{$\begin{array}{l}\text { RDA, recommended dietary allowances for women aged } 51-70 \text { years (National } \\
\text { Research Council, 1989; Standing Committee on the Scientific Evaluation of Dietary } \\
\text { Reference Intakes, 1997); RE, retinol equivalents; } \alpha \text {-TE, } \alpha \text {-tocopherol equivalents. } \\
\text { *For details of subjects and procedures, see Table } 1 \text { and pp. } 268-269 \text {. } \\
\text { † No RDA has been given. Si levels in cows' milk were found to be about } 400 \mu \mathrm{g} / \mathrm{l} \\
\text { (Anderson, 1992). }\end{array}$} \\
\hline
\end{tabular}


after extraction with hydroxyapatite, respectively (IRMA; Medgenix-H-Ost, Fleurus, Belgium; intra-and inter-assay $\mathrm{CV}$ were $3.1 \%$ and $6.4 \%$, respectively). Carboxylated osteocalcin is calculated as the difference between undercarboxylated osteocalcin and total osteocalcin. Calcitonin (RIA; Nichols Institute, San Juan Capistrano, CA, USA; intra-and inter-assay CV were $3.5 \%$ and $6.3 \%$ respectively), intact PTH (IRMA; Nichols Institute; intra- and inter-assay $\mathrm{CV}$ were $3.5 \%$ and $6.0 \%$, respectively) and 25(OH)D (competitive protein binding assay (Chen et al. 1990); intra- and inter-assay CV were $10.0 \%$ and $16.0 \%$, respectively) were determined because they are important (pre-) hormones in bone metabolism. Urine was analysed for $\mathrm{Ca}$, phosphate, creatinine (Mega, Merck or Vitros; Johnson \& Johnson) and for D-Pyr (HPLC (Beardsworth et al. 1990); intra-and inter-assay CV was $6.0 \%$, the CV within and between 3 -week analyses were $<12 \%$ and $<15 \%$, respectively). The urinary excretion of D-Pyr and $\mathrm{Ca}$ was corrected for urinary creatinine. Premenopausal D-Pyr reference value (University Hospital Groningen) was $11.7 \mu \mathrm{mol} / \mathrm{mol}$ creatinine (95\% CI 6.8, 23.1).

\section{Statistics}

Sample size per group was calculated based upon a small pilot study (Schaafsma \& Pakan, 1999). For this study, we calculated that at a $95 \%$ level of significance and $90 \%$ power, twenty-one women per group were needed to detect a difference of $1.4 \%$ in BMD of the femoral neck between intervention and placebo group. We aimed to include twenty-five women per group.

Allocation to the different intervention groups was based on computer-generated random numbers. Data were analysed using SPSS 7.0 (SPSS Inc., Chicago, USA).

Before the main analysis, P1NP, body weight and postmenopausal years at baseline were identified as potential confounders by forward multiple regression. However, the variables appeared not to be of significant importance in the univariate general linear model, using the change in femoral neck BMD as dependent variable. Therefore, these confounders were not taken into consideration during the main analysis, in order to keep the model as simple as possible.

Some of the parameters (post-menopausal age, weight, BMI, P1NP, calcitonin, PTH, and BMD lumbar spine) were found to have non-parametric distributions according to the Kolmogorov-Smirnov normality test. For that reason, all parameters were evaluated with non-parametric, two-tailed statistical tests. Differences between the groups were studied with the Kruskal-Wallis test combined with the Mann-Whitney U-test. Differences between repeated measurements within the groups were identified with the Wilcoxon signed-rank test. Associations between baseline values of parameters and their changes after 12 months were studied with the Spearman rank test. Differences were considered significant when $P \leq 0 \cdot 05$. Changes in parameters were calculated as percentage change from baseline.

\section{Results}

Age, compliance, calcium intake and routine parameters

Although the women were recruited from the same population and randomly allocated to one of the three groups, women in groups A and B were significantly younger than those in group C. Furthermore, group A had a significantly lower post-menopausal age compared with group C (Table 1). The number of women with a post-menopausal age less than 10 years in groups $\mathrm{A}, \mathrm{B}$ and $\mathrm{C}$ accounted for 58,45 and $15 \%$, respectively. These differences in age and post-menopausal age, however, were not associated (Spearman rank test) with changes in BMD at any site. Mean compliance with intervention in groups A, B and $\mathrm{C}$ was 97 (range 90.8-100)\%, 98.4 (93.4-100)\% and $97(82.4-100) \%$, respectively. The calculated $\mathrm{Ca}$ intake of the participants in the present study was unexpectedly high (1294 (SD 421) mg/d) when compared with the mean Dutch (Dutch National Food Consumption

Table 3. Bone mineral densities $\left(\mathrm{g} / \mathrm{cm}^{2}\right)$ at baseline and their percentage changes after 12 months of intervention*

(Mean values with their standard deviations)

\begin{tabular}{|c|c|c|c|c|c|c|}
\hline \multirow{2}{*}{$\begin{array}{l}\text { Group... } \\
\text { Site of measurement }\end{array}$} & \multicolumn{2}{|c|}{ A } & \multicolumn{2}{|c|}{ B } & \multicolumn{2}{|c|}{ C } \\
\hline & Mean & SD & Mean & SD & Mean & SD \\
\hline Lumbar spine: Baseline & 0.936 & 0.105 & 0.966 & 0.099 & 0.968 & 0.129 \\
\hline Change (\%) & 0.10 & $2 \cdot 14$ & 0.52 & 2.07 & $0 \cdot 13$ & $2 \cdot 31$ \\
\hline Femoral neck: Baseline & 0.741 & 0.095 & 0.741 & 0.095 & 0.792 & 0.114 \\
\hline Change (\%) & $1 \cdot 75 \dagger \ddagger$ & 3.91 & $1 \cdot 16$ & 5.09 & -0.60 & 3.50 \\
\hline Total proximal femur: Baseline & 0.864 & 0.099 & 0.883 & 0.121 & 0.917 & $0 \cdot 120$ \\
\hline Change (\%) & 0.23 & 3.59 & 0.23 & 3.57 & -0.14 & $4 \cdot 34$ \\
\hline Trochanter: Baseline & 0.649 & 0.073 & 0.671 & 0.092 & 0.696 & 0.091 \\
\hline Change (\%) & -0.31 & 3.00 & -0.46 & $5 \cdot 24$ & 0.57 & 6.47 \\
\hline Intertrochanter: Baseline & 1.016 & 0.126 & 1.038 & 0.156 & 1.073 & 0.159 \\
\hline Change (\%) & 0.20 & 3.94 & 0.29 & 4.53 & -0.28 & 4.85 \\
\hline Ward's triangle: Baseline & 0.592 & 0.138 & 0.539 & 0.125 & 0.609 & 0.129 \\
\hline Change (\%) & $3.38+\dagger$ & 5.07 & 4.08 & $10 \cdot 76$ & -0.50 & $6 \cdot 24$ \\
\hline
\end{tabular}

* For details of subjects and procedure, see Tables 1 and 2 and pp. 268-269.

Mean values at 12 months were significantly different from those at baseline: $\uparrow P=0.013, \uparrow \uparrow P=0.006$.

Mean change at 12 months was significantly different from that of group $C$ : $\ddagger P=0.014$. 
Survey, 1998) daily Ca intake by 50-65-year-old women (995 mg). Habitual Ca intake did not differ between the groups at baseline and did not change during the study. No significant differences were found in body weight, height, and BMI between the groups at baseline (Table 1) nor were changes observed during the study. Serum concentrations of $\mathrm{Ca}$, phosphate, creatinine, albumin and the enzymes $\gamma$ glutamyl transferase, alanine amino transferase and aspartate amino transferase also did not change during the study (result not shown).

\section{Bone mineral density}

Despite the age differences between the groups, BMD baseline values were not significantly different (Table 3). After 12 months of intervention, BMD of femoral neck and of Ward's triangle had increased significantly in group A compared with baseline. No significant changes were seen in BMD at other sites nor in groups B and C. No differences were found between groups $\mathrm{A}$ and B. The increase in BMD of the femoral neck in group A was significantly different from the decrease in group $\mathrm{C}$, which is in accordance with the calculated statistical power of the study.

Effects of baseline BMD on BMD changes after 12 months were studied for the combined groups A and B, since these groups only differed in Ca source. Low baseline BMD in groups A and B were associated $(P<0 \cdot 01)$ with larger increases or smaller losses after 12 months in case of the intertrochanter $(r-0.45)$, total proximal femur $(r-0.39)$, and the Ward's triangle $(r-0.41)$. In contrast, lumbar spine BMD increased more or decreased less when baseline BMD was higher $(r$ 0.39, $P<0.01)$. No significant correlations were found for the femoral neck and trochanter.

\section{Biochemical markers}

Baseline values of biochemical markers and changes (\%) after 12 months are reported in Table 4. Only one woman in group $\mathrm{C}$ had a marginal $(25-40 \mathrm{nmol} / \mathrm{l}$ (Vieth, 1999)) 25(OH)D level at baseline. All three groups had increased their serum $25(\mathrm{OH}) \mathrm{D}$ levels significantly at the end of the study. For group $\mathrm{C}$, the increase is probably due to the summer, since this group was not supplemented with vitamin D. During the winter months, the mean $25(\mathrm{OH}) \mathrm{D}$ level in group $\mathrm{C}$ decreased by $26 \%$ to $67 \mathrm{nmol} / \mathrm{l}$. Both intervention groups did not show a winter dip of $25(\mathrm{OH}) \mathrm{D}$. In both supplemented groups, serum levels of P1NP and PTH decreased significantly compared with baseline. The percentage changes in P1NP and PTH were also different from the percentage changes in group C. No differences were found in levels of total osteocalcin. Carboxylated osteocalcin increased during the study in group B. A significant decrease in D-Pyr excretion was found in group A. This group also had the highest baseline excretion of D-Pyr. Group C showed a small but significant increase in bone-specific alkaline phosphatase compared with baseline and compared with groups A and B. No differences were found between groups $\mathrm{A}$ and $\mathrm{B}$ in changes and absolute levels of biochemical parameters at 12 months. Only at 6 months was the decrease in D-Pyr significantly $(P=0.04)$ greater in group A compared with group B (result not shown).

When groups $\mathrm{A}$ and $\mathrm{B}$ were combined, all baseline

Table 4. Biochemical parameters at baseline and percentage changes from baseline after 12 months of intervention* (Mean values with their standard deviations)

\begin{tabular}{|c|c|c|c|c|c|c|c|c|}
\hline \multirow{2}{*}{$\begin{array}{l}\text { Group... } \\
\text { Parameter }\end{array}$} & \multicolumn{2}{|c|}{ A } & \multicolumn{2}{|c|}{$\mathrm{B}$} & \multicolumn{2}{|c|}{ C } & \multicolumn{2}{|c|}{$P$ value } \\
\hline & Mean & SD & Mean & SD & Mean & SD & $A v \cdot C$ & B v. C \\
\hline b-ALP (U/I) Baseline & $16 \cdot 2$ & 4.5 & $17 \cdot 4$ & $6 \cdot 4$ & $14 \cdot 8$ & $3 \cdot 8$ & & \\
\hline Change $(\%)$ & $2 \cdot 2$ & 12.5 & $-2 \cdot 8$ & $21 \cdot 6$ & 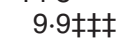 & $13 \cdot 3$ & 0.015 & 0.012 \\
\hline P1NP $(\mu \mathrm{g} / \mathrm{l})$ Baseline & 45.9 & $14 \cdot 3$ & $47 \cdot 2$ & 20.5 & $37 \cdot 0$ & $13 \cdot 3$ & & \\
\hline Change (\%) & $-17 \cdot 6$ 㧊 & 23.2 & -18.2㧊 & 19.5 & -7.0 & $21 \cdot 0$ & 0.029 & 0.015 \\
\hline Calcitonin (ng/l) Baseline & 8.1 & 3.5 & 8.0 & 2.6 & $6 \cdot 4$ & 2.5 & & \\
\hline Change (\%) & 8.7 & 37.4 & $-4 \cdot 0$ & $17 \cdot 7$ & $8 \cdot 4$ & 25.5 & & \\
\hline Intact-PTH (pmol//) Baseline & 5.5 & 1.3 & $5 \cdot 8$ & 1.9 & $5 \cdot 4$ & 1.7 & & \\
\hline Change $(\%)$ & $-15.4 \ddagger$ & $26 \cdot 6$ & $-19 \cdot 5 \ddagger$ & $42 \cdot 6$ & 6.5 & $35 \cdot 3$ & 0.019 & 0.010 \\
\hline Calcidiol (nmol/l) Baseline & $97 \cdot 1$ & $24 \cdot 1$ & $83 \cdot 1$ & $22 \cdot 4$ & 91.0 & $36 \cdot 5$ & & \\
\hline Change $(\%)$ & $25 \cdot 1$ 抹 & 29.8 & $43 \cdot 8$ 抹 & $27 \cdot 3$ & $11 \cdot 1 \neq$ & $22 \cdot 7$ & & 0.000 \\
\hline D-Pyr ( $\mu \mathrm{mol} / \mathrm{mol}$ Creatinine) Baseline & $15 \cdot 0$ & 4.3 & $12 \cdot 6$ & 3.2 & $12 \cdot 2^{+}$ & $3 \cdot 8$ & 0.023 & \\
\hline Change $(\%)$ & $-14 \cdot 9 \ddagger \ddagger$ & $25 \cdot 1$ & $-2 \cdot 4$ & $26 \cdot 9$ & 1.6 & $23 \cdot 6$ & 0.011 & \\
\hline$\%$ carbOC (\%) Baseline & $67 \cdot 3$ & 9.0 & $67 \cdot 1$ & 7.4 & $66 \cdot 4$ & $10 \cdot 2$ & & \\
\hline Change $(\%)$ & 5.0 & $12 \cdot 3$ & $6.9 \ddagger$ & $14 \cdot 3$ & $-1 \cdot 8$ & $15 \cdot 8$ & & 0.014 \\
\hline Total osteocalcin $(\mu \mathrm{g} / \mathrm{l})$ Baseline & 13.9 & $5 \cdot 2$ & $13.9^{+}$ & 4.1 & $12 \cdot 4$ & 4.4 & & \\
\hline Change (\%) & -1.7 & $26 \cdot 7$ & -2.4 & $24 \cdot 8$ & 0.4 & $17 \cdot 7$ & & \\
\hline Urinary Ca:creatinine $(\mathrm{mol} / \mathrm{mol})$ Baseline & 0.44 & 0.31 & 0.42 & 0.18 & 0.37 & 0.23 & & \\
\hline Change (\%) & $10 \cdot 9$ & 70.9 & $23 \cdot 4$ & 74.5 & -0.2 & 56.7 & & \\
\hline
\end{tabular}

b-ALP, bone-specific alkaline phosphatase; P1NP, amino-terminal propeptide extension of type I collagen; PTH, parathyroid hormone; D-Pyr, deoxypyridinoline; $\%$ carbOC, carboxylated osteocalcin.

${ }^{*}$ For details of subjects and procedures, see Tables 1 and 2 and pp. 268-269.

† Mann-Whitney $U$ test between the groups.

Baseline and 12 month levels of parameters were significantly different within the group $\ddagger P \leq 0 \cdot 05, \ddagger \ddagger P \leq 0 \cdot 01, \neq \ddagger \ddagger P \leq 0.001$ (Wilcoxon signed rank test). 
values of biochemical markers were significantly and negatively correlated $(r-0.33$ to $-0 \cdot 80)$ with the changes after 6 (except for calcitonin) and 12 months of supplementation. For the parameters P1NP, D-Pyr and PTH this means that decreases were stronger where baseline values were higher (Fig. 1). No correlation was found between baseline PTH and baseline $25(\mathrm{OH}) \mathrm{D}$, nor between their changes after 12 months of study. However, in group B alone, larger increases in $25(\mathrm{OH}) \mathrm{D}$ during the study were associated with larger decreases in PTH $(r-0.42$, $P \leq 0 \cdot 05)$.

Only two significant correlations were found between $\mathrm{BMD}$ and biochemical parameters in the combined groups A and B. Firstly, the increase in femoral neck $\mathrm{BMD}$ was associated with a decrease in D-Pyr excretion
( $r-0.32, P<0.05)$. Secondly, BMD of the trochanter showed a higher increase or a smaller decrease when serum PTH decreased more $(r-0 \cdot 34, P<0 \cdot 05)$. These correlations were especially an effect of group $\mathrm{B}$.

\section{Discussion}

We investigated the effects of daily supplements with different $\mathrm{Ca}$ sources (chicken eggshell powder: group A, $n$ 24; purified $\mathrm{CaCO}_{3}$ : group $\mathrm{B}, n$ 22) but equal amounts of cholecalciferol, phylloquinone, $\mathrm{Mg}$ and other vitamins and minerals (Table 2), in healthy post-menopausal women aged 50-70 years (Table 1) during 1 year. Untreated post-menopausal women (group C, $n$ 27) served as controls. The major finding at the study end
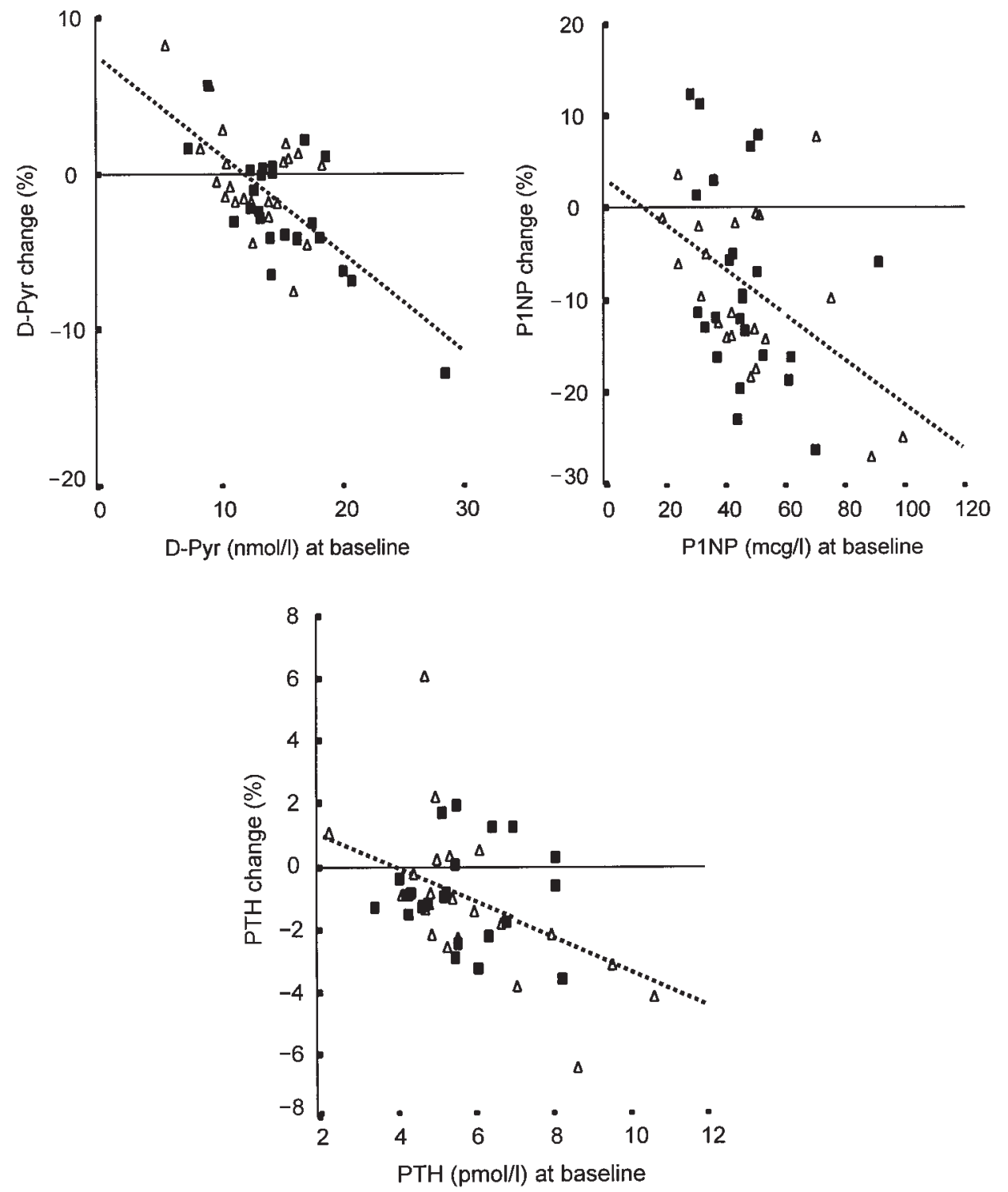

Fig. 1. Correlations between baseline levels of deoxypyrimidoline (D-Pyr; $R^{2} 0.46, r-0.46, P<0.01$ ), amino-terminal propeptide extension of type I collagen (P1NP; $\left.R^{2} 0.18, r-0.42, P<0.01\right)$ and parathyroid hormone (PTH; $\left.R^{2} 0.19, r-0.36, P<0.05\right)$ and their percent changes after 12 months of intervention. Changes in parameters were obtained by subtracting baseline from 12 month values. The calculated difference was expressed as a percentage from baseline. For a description of the groups A and B, see Table 1; for the supplements, see Table 2. The regression line (---) accounts for the combined groups A and B. (ם) Group A; $(\triangle)$ Group B. 
was an increased BMD of the femoral neck in group A compared with group C. Compared with baseline, group A exhibited an increase of BMD in the Ward's triangle and femoral neck (Table 3). Changes in BMD were not different between groups A and B. Both groups exhibited changes in serum markers of bone resorption (D-Pyr), bone formation (P1NP) and the 25(OH)D-PTH axis (Table 4), all together suggesting a reduction of bone turnover. Since both an increase of BMD and a reduction of bone turnover (Lauritzen, 1996; Kanis, 1999) are associated with increased bone strength and reduced fracture risk (Compston, 1995; Dawson-Hughes, 1998), we conclude that the supplements used in groups A and B are likely to be beneficial for bone health. It must be pointed out that BMD changes did not reach significance in group B, which might be due to somewhat smaller subject numbers.

Negative correlations between baseline BMD of the hip and changes after 12 months indicate a higher responsiveness of women with low baseline BMD to additional minerals and vitamins. Biochemical parameters of bone turnover also showed such negative correlations between baseline and changes after 12 months (Fig. 1). These associations suggest that especially women with high bone turnover and/or lower baseline BMD of the hip benefited from the supplementation. The encountered positive correlation between baseline BMD of the lumbar spine and change after 12 months can possibly be explained by a higher transient remodelling effect (Heaney, 1996). It is possible that a higher BMD accounts for a larger surface area of trabecular bone and consequently more resorption cavities to fill.

Although increases in BMD of the femoral neck and Ward's triangle in group A suggest an increased femoral strength we did not observe effects on BMD of the trochanter. This might be of importance, since the strength of the femoral neck seems rather predicted by an increase in BMD of the trochanter than by that of the femoral neck itself (Cheng et al. 1997). Our results are in line with those of Reid et al. (1995), who also found no changes in trochanter BMD, following a 1 year supplementation of women 10 years past menopause with $1000 \mathrm{mg} \mathrm{Ca} / \mathrm{d}$. A slight increase from baseline was however noticed after 4 years of supplementation. It is therefore possible that prolonged use of the present supplements may also have favourable effects on trochanter BMD.

Both the Ward's triangle and lumbar spine are mostly composed of trabecular bone, whereas the femoral neck contains more cortical bone (Wood \& Fleet, 1998). Trabecular bone often responds better to $\mathrm{Ca}$ supplementation than cortical bone (Kanis, 1999), and it is therefore not clear why we merely observed increases in BMD of the Ward's triangle and femoral neck and not of the lumbar spine. The relatively low post-menopausal age of the present study population might be a factor in this respect. It is known that oestrogen deficiency during the first 5-10 years past menopause results primarily in a loss of trabecular bone and this loss is poorly responsive to nutritional intervention (Compston, 1995; Ohta, et al. 1996). Studies (Dawson-Hughes et al. 1990; Nelson et al. 1991) with 3-13 years post-menopausal women support this statement but also show that the effect of oestrogen deficiency on trabecular bone might even persist longer than 10 years past menopause. Fifty-eight percent of group A and $45 \%$ of group B had post-menopausal ages below 10 years. This interpretation does not, however, provide us with an explanation for the observed increase of Ward's triangle BMD. It is also possible that the increase of femoral neck BMD, but not the lumbar spine, is caused by an increased intake of $\mathrm{Mg}$ and/or a decreased serum level of PTH. Mg supplementation of post-menopausal women with $500 \mathrm{mg}$ $\mathrm{Mg} / \mathrm{d}$ for 2 years gave rise to an increase of especially the BMD of the femoral neck (Rude \& Olerich, 1996). A high PTH level in post-menopausal women is caused by oestrogen deficiency, low vitamin $\mathrm{D}$ status and/or low $\mathrm{Ca}$ intake and is regarded to decrease especially BMD of cortical bone (Compston, 1995; McKenna \& Freaney, 1998). In this respect it is important to note that serum $25(\mathrm{OH}) \mathrm{D}$ levels in the supplemented groups reached values above $100 \mathrm{nmol} / \mathrm{l}$, which did not decline during the winter months. These levels are regarded to cause the lowest achievable PTH levels at a given Ca intake (McKenna \& Freaney, 1998). Furthermore, the decrease of PTH may partially be due to the increased Ca intake (up to $2300 \mathrm{mg} / \mathrm{d}$ ), since a daily intake of over $2000 \mathrm{mg}$ Ca by elderly women was found to reduce PTH to premenopausal values (McKane et al. 1996).

Directly after menopause, bone turnover increases with an excess of bone resorption (Allolio, 1999) reflected in a higher urinary D-Pyr excretion. The older women in the placebo group therefore probably lost less bone than was to be expected in the younger women in group B and group $\mathrm{A}$ in particular. In agreement with their lower post-menopausal age, higher D-Pyr levels in group A at baseline, compared with group C (Table 4), probably indicate a higher bone turnover. At the same time, the lower levels of biochemical markers in group $\mathrm{C}$ may be explained by a gradual decrease of oestrogen deficiency-related bone turnover with advancing post-menopausal age (Ohta et al. 1996). The urinary D-Pyr excretion in group A decreased within 6 months to levels found in groups B and C, which were close to premenopausal reference values as used by the University Hospital of Groningen. Both groups A and B showed a decrease of P1NP levels, which is a marker of bone formation and therefore of bone turnover. Taken together these data suggest that the supplements taken by groups $\mathrm{A}$ and $\mathrm{B}$, reduce bone turnover. Recently it has been reported that short-term changes in biochemical markers may predict long-term changes in BMD (Ravn et al. 1999). The supplements are therefore likely to change the balance of bone resorption and bone formation towards the latter especially when baseline turnover is high. This effect is shown particularly in group A with increases in BMD at certain sites.

Although the focus of this discussion is on $\mathrm{Ca}, \mathrm{Mg}$, cholecalciferol and phylloquinone, other vitamins and minerals were present, and we cannot exclude that they did not influence the final results in some way. However, effects can be explained for the major part by the four key ingredients (Schaafsma et al. 2001). A second point of discussion is the compositional difference between chicken eggshell powder and purified $\mathrm{CaCO}_{3}$. A beneficial 
characteristic of chicken eggshell powder may be the relatively high levels of $\mathrm{Sr}$; normal daily $\mathrm{Sr}$ intake increases 15-40\%/g eggshell powder consumed. Although this chronic loading with $\mathrm{Sr}$ may be stimulatory for bone formation in the long-term, the intakes are 400 to 800 times lower than the amounts used in therapeutic studies (Schaafsma et al. 2001).

We conclude that in healthy women, close to 10 years past menopause, supplementation with minerals and vitamins, and $\mathrm{Ca}, \mathrm{Mg}$, vitamin $\mathrm{D}$ and vitamin $\mathrm{K}$ in particular, increases BMD of the femoral neck and Ward's triangle. Favourable effects on BMD are supported by decreases in parameters of bone turnover. The present study also suggests, based on changes from baseline and compared with placebo, that eggshell powder may be preferred over purified $\mathrm{CaCO}_{3}$ as a source of $\mathrm{Ca}$. This suggestion, however, warrants further research with statistical power based on the outcome of the present study.

\section{Acknowledgements}

We would like to thank all the women who participated in the study and Alice Rodenburg for her outstanding technical and organising assistance. Furthermore, we appreciated the cooperation of the general practitioners A.G. Swart, S. Wiarda and P. Sikkens. The latter we also would like to thank for placing his practice at our disposal during sampling. We are grateful to D.A. Piers, MD, PhD, J.J. Pratt, $\mathrm{PhD}$, and their co-workers for the measurements of BMD and several biochemical parameters. Finally, we would like to thank W.H.M. Saris, MD, PhD (University Maastricht) and P.J.F. de Vries, PhD (Friesland Coberco Dairy Foods) for their critical comments on the manuscript.

\section{References}

Allolio B (1999) Risk factors for hip fracture not related to bone mass and their therapeutic implications. Osteoporosis International 9, s9-s16.

Anderson RR (1992) Comparison of trace elements in milk of four species. Journal of Dairy Science 75, 3050-3055.

Aurbach GD (1988) Calcium-regulating hormones: parathyroid hormone and calcitonin. In Calcium in Human Biology, pp. 43-68 [BEC Nordin, editor]. Berlin-Heidelberg: SpringerVerlag.

Beardsworth CJ, Eyre DR \& Dickson JR (1990) Changes with age in the urinary excretion of lysyl- and hydroxylysyl pyridinoline, two new markers of bone collagen turnover. Journal of Bone and Mineral Research 5, 671-676.

Boskey AL, Gadaleta S, Gundberg C, Doty SB, Ducy P \& Karsenty G (1998) Fourier transform infrared microspectroscopic analysis of bones of osteocalcin-deficient mice provides insight into the function of osteocalcin. Bone 23, 187-196.

Cabrera CD, Henríquez MS, Traba ML, Villafaña EA \& De La Piedra C (1998) Biochemical markers of bone formation in the study of postmenopausal osteoporosis. Osteoporosis International 8, 147-151.

Chen TC, Turner AK \& Holick MF (1990) Methods for the determination of circulating concentration of 25-hydroxyvitamin D. Journal of Nutrition and Biochemistry 1, 315-319.

Cheng XG, Lowet G, Boonen S, Nicholson PHF, Brys P, Nijs J \& Dequeker J (1997) Assessment of the strength of proximal femur in vitro: relationship to femoral bone mineral density and femoral geometry. Bone 20, 213-218.

Compston JE (1995) The role of vitamin D and calcium supplementation in the prevention of osteoporotic fractures in the elderly. Clinical Endocrinology 43, 393-405.

Dawson-Hughes B (1998) Vitamin D and calcium: recommended intake for bone health. Osteoporosis International 8, s30-s34.

Dawson-Hughes B, Dallal GE, Krall EA, Sadowski L, Sahyoun N \& Tannenbaum S (1990) A controlled trial of the effect of calcium supplementation on bone density in postmenopausal women. New England Journal of Medicine 323, 878-883.

Dawson-Hughes B, Harris SS, Krall EA \& Dallal GE (1997) Effect of calcium and vitamin D supplementation on bone density in men and women 65 years of age or older. New England Journal of Medicine 337, 670-676.

Delmas PD (1991) What do we know about biochemical bone markers? Clinical Obstetrics and Gynaecology 5, 817-830.

Douglas AS, Robins SP, Hutchison JD, Porter RW, Stewart A \& Reid DM (1995) Carboxylation of osteocalcin in post-menopausal women following vitamin $\mathrm{K}$ and $\mathrm{D}$ supplementation. Bone 17, 15-20.

Driessens FCM \& Verbeeck RMH (1988) On the prevention and treatment of calcification disorders of old age. Medical Hypotheses 25, 131-137.

Dutch National Food Consumption Survey (1998) Zo eet Nederland. Resultaten van de Voedselconsumptiepeiling 19971998, p. 199. Delft: Van Marken Delft Drukkers.

Heaney RP (1996) Nutrition and risk for osteoporosis. In Osteoporosis, pp. 483-509 [R Marcus, D Feldman and J Kelsey, editors]. San Diego: Academic Press.

Kanis JA (1999) The use of calcium in the management of osteoporosis. Bone 24, 279-290.

Lauritzen JB (1996) Hip fractures: incidence, risk factors, energy absorption, and prevention. Bone 18, s65-s75.

McKane WR, Khosla S, O'Fallon WM, Robins SP, Burritt MF \& Riggs BL (1996) A high calcium intake reverses the secondary hyperparathyroidism and increased bone resorption of elderly women. Journal of Clinical Endocrinology and Metabolism 81, 1699-1703.

McKenna MJ \& Freaney R (1998) Secondary hyperparathyroidism in the elderly: means to defining hypovitaminosis D. Osteoporosis International 8, s3-s6.

Makai F \& Chudacek J (1991) The treatment of osteoporosis with Biomin-H. Archives of Gerontology and Geriatrics 2, 487-490.

National Osteoporosis Foundation (1999) Osteoporosis in men. Osteoporosis Clinical Updates 2, 3.

National Research Council (1989) Recommended Dietary Allowances. Washington, DC: National Academy Press.

Nelson ME, Fisher EC, Dilmanian FA, Dallal GE \& Evans WJ (1991) A 1-y walking program and increased dietary calcium in postmenopausal women: effects on bone. American Journal of Clinical Nutrition 53, 1304-1311.

Ohta H, Sugimoto I, Masuda A, Komukai S, Suda Y, Makita K, Takamatsu K, Horiguchi F \& Nozawa S (1996) Decreased bone mineral density associated with early menopause progresses for at least ten years: cross-sectional comparisons between early and normal menopausal women. Bone 18, 227-231.

Prince R, Devine A, Dick I, Criddle A, Kerr D, Kent N, Price R \& Randell A (1995) The effects of calcium supplementation (milk powder or tablets) and exercise on bone density in postmenopausal women. Journal of Bone and Mineral Research 10, $1068-1075$.

Ravn P, Clemmesen B \& Christiansen C (1999) Biochemical markers can predict the response in bone mass during alendronate treatment in early postmenopausal women. Bone 24, 237-244.

Reginster JY, Halkin V, Henrotin Y \& Gosset C (1999) Treatment 
of osteoporosis: role of bone-forming agents. Osteoporosis International 3, s91-s96.

Reid IR, Ames RW, Evans MC, Gamble GD \& Sharpe SJ (1995) Long-term effects of calcium supplementation on bone loss and fractures in postmenopausal women: a randomized controlled trial. American Journal of Medicine 98, 331-335.

Riggs LB, O'Fallon MW, Muhs J, O'Connor MK, Kumar R \& Melton JL (1998) Long-term effects of calcium supplementation on serum parathyroid hormone level, bone turnover, and bone loss in elderly women. Journal of Bone and Mineral Research 13, 168-174.

Rude RK \& Olerich M (1996) Magnesium deficiency: possible role in osteoporosis associated with gluten-sensitive enteropathy. Osteoporosis International 6, 453-461.

Schaafsma A \& Beelen GM (1999) Eggshell powder, a comparable or better source of calcium than purified calcium carbonate: piglet studies. Journal of the Science of Food and Agriculture 79, 1-5.

Schaafsma A, de Vries PJF \& Saris WHM (2001) Delay of natural bone loss by higher intakes of specific minerals and vitamins. Critical Reviews in Food Science and Nutrition 41, 225-249.

Schaafsma A, Muskiet FAJ, Storm H, Hofstede GJH, Pakan I \& Van der Veer E (2000) Vitamin $\mathrm{D}_{3}$ and vitamin $\mathrm{K}_{1}$ supplementation of Dutch postmenopausal women with normal and low bone mineral densities: effects on serum 25-hydroxyvitamin D and carboxylated osteocalcin. European Journal of Clinical Nutrition 54, 626-631.

Schaafsma A \& Pakan I (1999) Short-term effects of a chicken egg shell powder enriched dairy product on bone mineral density in persons with osteoporosis or osteopenia. Bratislavské Lekárske Listy 7, 651-656.

Sokoll LJ, Booth SL, O'Brien ME, Davidson KW, Tsaioun KI \& Sadowski JA (1997) Changes in serum osteocalcin, plasma phylloquinone, and urinary -carboxyglutamic acid in response to altered intakes of dietary phylloquinone in human subjects. American Journal of Clinical Nutrition 65, 779-784.

Standing Committee on the Scientific Evaluation of Dietary Reference Intakes (1997) Dietary Reference Intakes: Calcium, Phosphorus, Magnesium, Vitamin D, and Fluoride. Washington DC: National Academy Press.

Stendig-Lindberg G, Tepper R \& Leichter I (1993) Trabecular bone density in a two year controlled trial of peroral magnesium in osteoporosis. Magnesium Research 6, 155-163.

Vieth R (1999) Vitamin D supplementation, 25-hydroxyvitamin D concentrations and safety. American Journal of Clinical Nutrition 69, 842-856.

Wood RJ \& Fleet JC (1998) The genetics of osteoporosis: vitamin D receptor polymorphisms. Annual Reviews of Nutrition 18, $233-258$. 